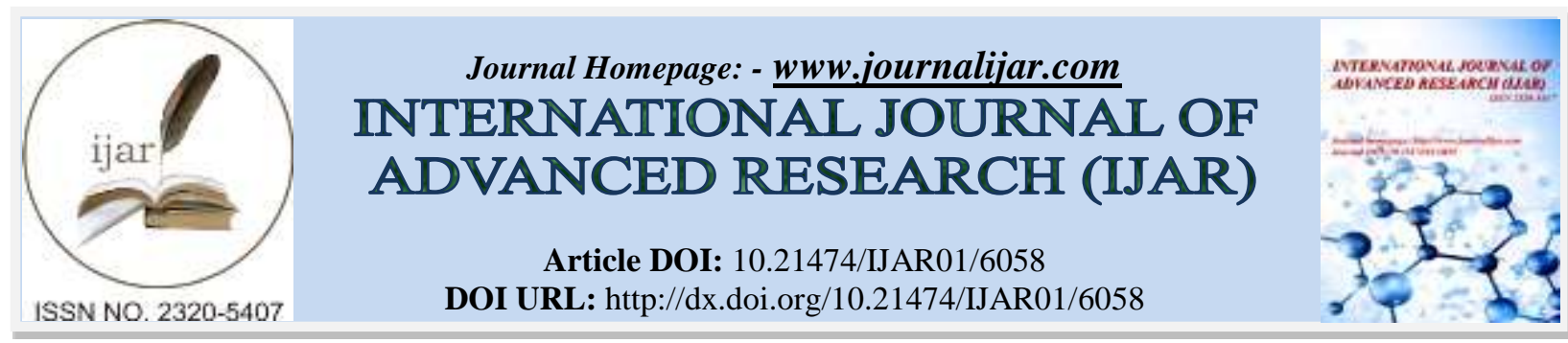

RESEARCH ARTICLE

\title{
THE DANGER OF DUAL ANTIPLATELET THERAPY IN A PATIENT WITH ACUTE EFFUSIVE CONSTRICTIVE PERICARDITIS WHO WAS SUBJECTED TO STENTING.
}

Samir Rafla and Sanaa Ashour.

Alexandria University, Faculty of Medicine, Cardiology department.

\section{Manuscript Info}

Manuscript History

Received: 14 October 2017

Final Accepted: 16 November 2017

Published: December 2017

Key words:-

Constrictive effusive pericarditis; dual antiplatelet therapy; acute myocardial infarction; primary stenting; iatrogenic errors.

\begin{abstract}
Background: Patients admitted with chest pain and electrocardiographic (ECG) changes have more than one possibility. Wrong diagnosis and management can lead to complications up to death.

Case presentation: A 55 year male presented with severe chest pain. ECG revealed raised ST segment in inferior leads. The PR segment depression of pericarditis was overlooked. The patient was admitted, received loading doses of dual antiplatelet (DAP) (ASA $300 \mathrm{mg} \&$ Clopidogrel $300 \mathrm{mg}$ ) plus heparin.

Clinical findings: Exam: B.P.: 110/70, T. $37{ }^{\circ} \mathrm{C}$. Normal jugular venous pulse (JVP). Heart: Normal. Echo revealed no regional wall motion abnormalities and no pericardial effusion. CKMB $=-\mathrm{ve}$, Troponin Zero.

Diagnostic assessments: Coronary angio revealed 95\% lesion in proximal RCA segment (Figure). Therapeutic interventions: Primary stenting was done. He was still complaining of the chest pain; 3 days later pericardial Rub was heard. ECHO revealed Large Pericardial effusion with no signs of tamponade. Ibuprofen (400 mg t.i.d.) + DAP with stomach protection.

Follow-up and outcomes: Three weeks later the patient was complaining of dyspnea grade III, no cyanosis. Cardio-thoracic surgery was consulted for open pericardiocentesis; 12 hours later, the patient's dyspnea became

Grade IV, his blood pressure was $80 / 50 \mathrm{mmHg}$ with pulsus paradoxus, $\mathrm{RR}=40$ cycles $/ \mathrm{min}$. The patient became anuric. Lab: $\mathrm{INR}=2.5, \mathrm{~K}=$ $6.9 \mathrm{mmol} / \mathrm{L}, B U N=87 \mathrm{mg} / \mathrm{dl}$, then $110, \mathrm{Cr}=3.5 \mathrm{mg} / \mathrm{dl}$, then 5 . $\mathrm{SGOT}=1023, \mathrm{SGPT}=501$. One session of hemodialysis was done. Patient arrested before open pericardiocentesis was done.

Conclusions: Acute pericarditis if subjected to dual antiplatelet therapy can lead to hemorrhagic pericardial effusion, then constrictive pericarditis and congestive heart failure.
\end{abstract}

Copy Right, IJAR, 2017,. All rights reserved.

\section{Background:-}

Patients admitted with chest pain and electrocardiographic (ECG) changes have more than one possibility. As the guidelines states that door to balloon time must be short (90 minutes), Borja Ibanez et al, ${ }^{(1)}$, the treating cardiologist 
may hurry in doing coronary angio. Problems arise when the physician finds significant lesion in major vessel nearly concordant with the ECG ST changes in spite the diagnosis is different.

\section{Case presentation:-}

Timeline: A 55 year male presented with severe chest pain. ECG revealed raised ST segment in inferior leads (figures 1,2). The PR segment depression of pericarditis was overlooked. The patient was admitted, received loading doses of dual antiplatelet (DAP) (ASA $300 \mathrm{mg} \&$ Clopidogrel $300 \mathrm{mg}$ ) plus heparin.
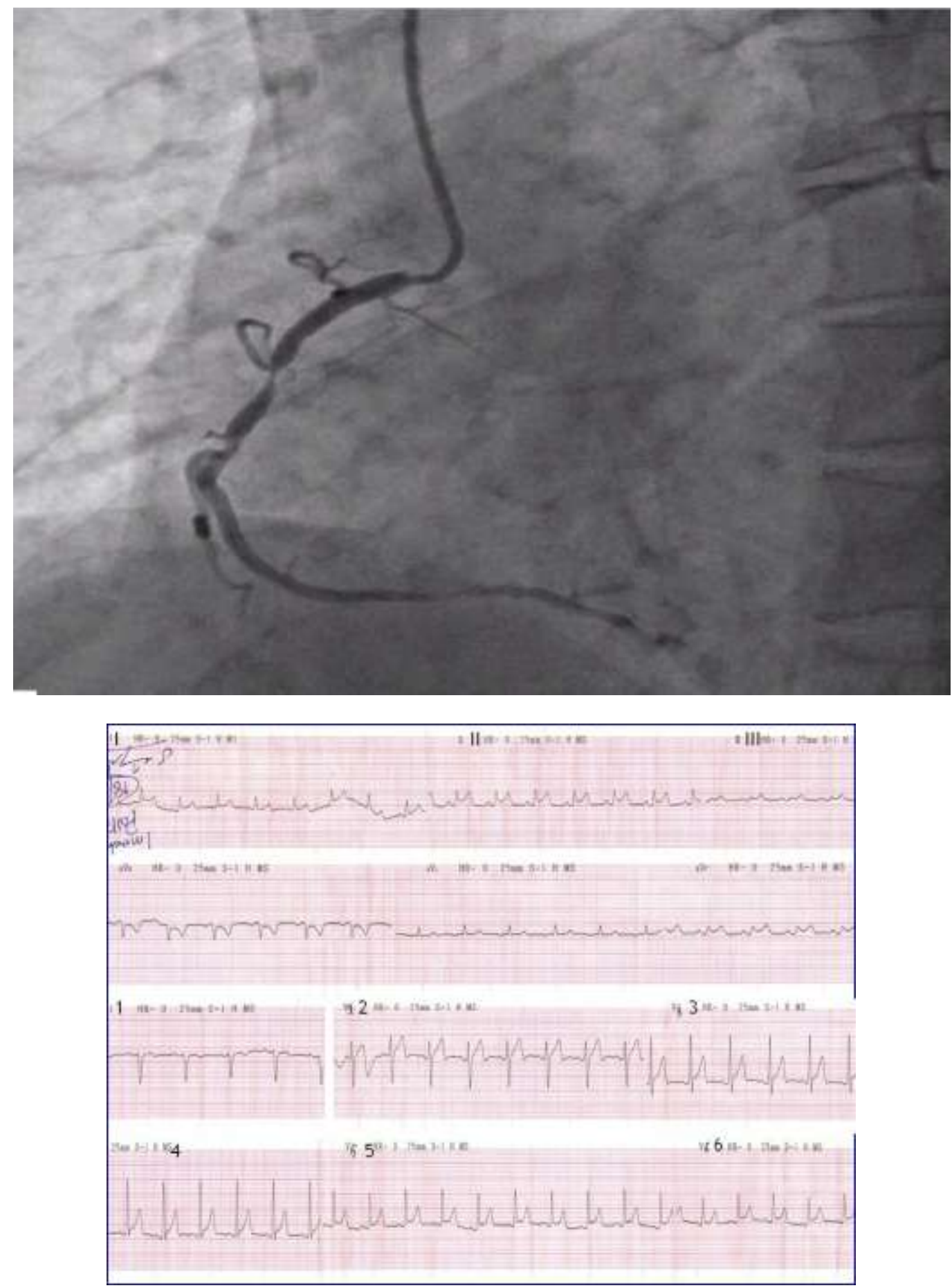


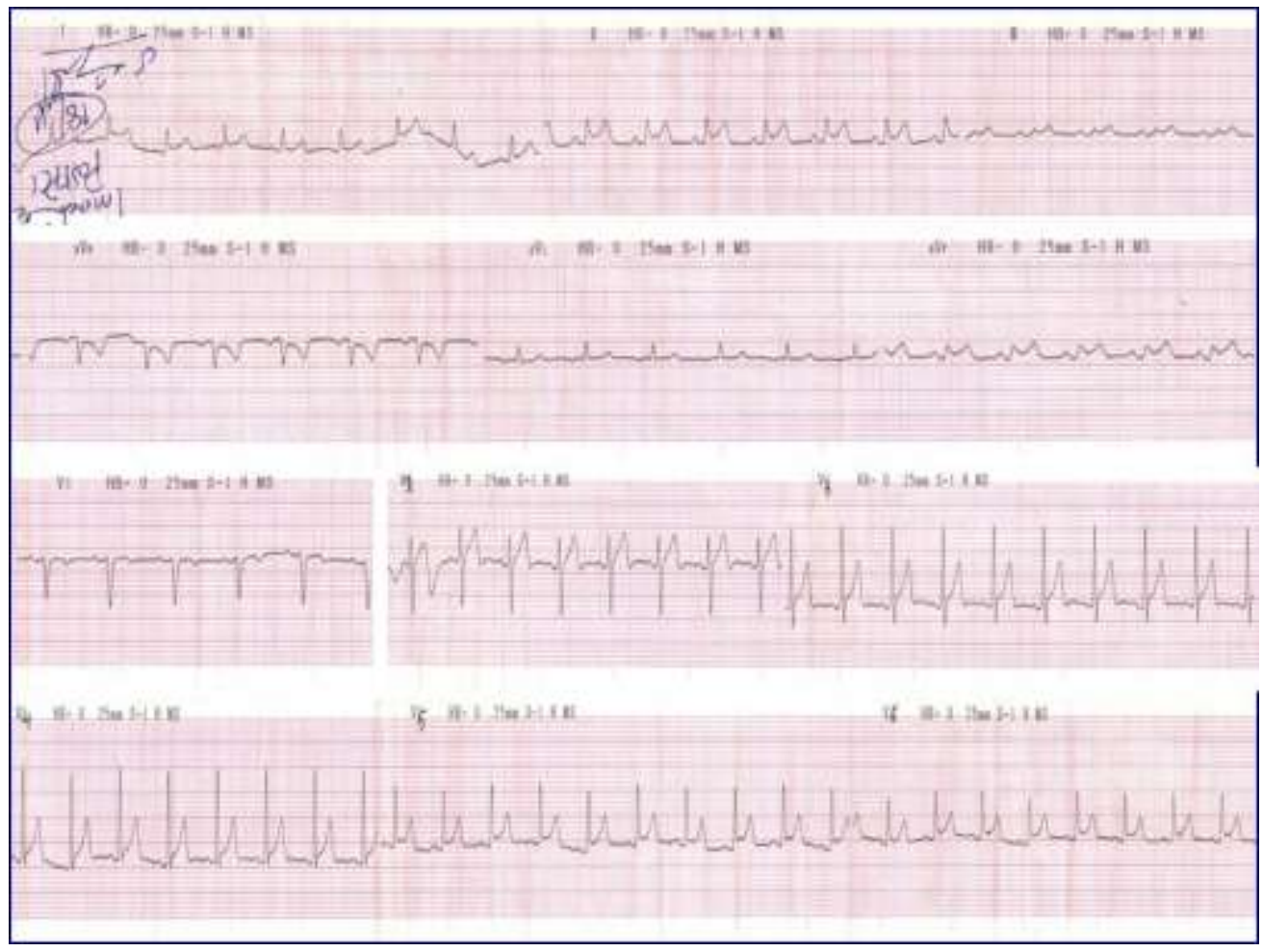

\section{Clinical findings:-}

Exam: B.P.: 110/70, T. $37{ }^{\circ} \mathrm{C}$. Normal jugular venous pulse (JVP). Heart: Normal. Echo revealed no regional wall motion abnormalities and no pericardial effusion. Lab. WBCs $=14,000$ cells per cubic millimeter, $\mathrm{Cr}=0.9 \mathrm{mg} / \mathrm{dl}$, $\mathrm{CKMB}=-\mathrm{ve}$, Troponin Zero. Patient was addict to Hashish (Cannabis) as well as heavy smoker.

Diagnostic assessments: Coronary angio revealed 95\% lesion in proximal RCA segment (Figure 3).

Therapeutic interventions: Primary stenting was done. He was still complaining of the chest pain; 3 days later pericardial Rub was heard. ECHO revealed Large Pericardial effusion with no signs of tamponade. Ibuprofen (400 mg t.i.d.) + DAP with stomach protection.

Follow-up and outcomes: Three weeks later the patient was complaining of dyspnea grade III, no cyanosis; congested JV up to the mandible. B.P. 105/60, tender liver. Lab: $\mathrm{Hb}=8 \mathrm{~g} / \mathrm{dl}$, WBCs $=14,000$ cells per cubic millimeter, Platelets $=398,000$ cells per cubic millimeter. INR $=1 . \mathrm{Cr}=1.2 \mathrm{mg} / \mathrm{dl}$, ESR 150, CRP $=152 \mathrm{mg} / \mathrm{l}$. The next day the patient's BP was $80 / 50 \mathrm{mmHg}$. He was given IV fluids. Cardio-thoracic surgery was consulted for open pericardiocentesis; 12 hours later, the patient's dyspnea became

Grade IV, his blood pressure was $80 / 50 \mathrm{mmHg}$ with pulsus paradoxus, $\mathrm{RR}=40$ cycles/min. The patient became anuric. $\mathrm{Lab}: \mathrm{INR}=2.5, \mathrm{~K}=6.9 \mathrm{mmol} / \mathrm{L}, \mathrm{BUN}=87$

$\mathrm{mg} / \mathrm{dl}$, then $110, \mathrm{Cr}=3.5 \mathrm{mg} / \mathrm{dl}$, then $5 . \mathrm{SGOT}=1023, \mathrm{SGPT}=501$. One session of hemodialysis was done. Patient arrested before open pericardiocentesis was done.

\section{Discussion:-}

Patients admitted with acute chest pain are in need of prompt investigations to reach correct diagnosis in short time. Mis-diagnosis can arise in several complex situations ${ }^{(1)}$ A Angelinia et al. ${ }^{(2)}$ Published case of myocarditis mimicking acute myocardial infarction.

Katharina Sonderegger-lseli ${ }^{(3)}$, reported that diagnostic errors were up to $20 \%$ but diminished with advances in diagnostic tools. 
A combination of Dual Antiplatelet therapy (DAPT) and anticoagulation is commonly prescribed, particularly in the setting of percutaneous coronary intervention (PCI). However, the same interventions designed to protect against such ischemic complications are responsible for the increased likelihood of major bleeding during hospitalization (Wallentin L et al. ${ }^{(4)}$ ). Pericarditis can result from extensive myocardial infarction (Widimský P et al ${ }^{(5)}$.), or as in our case pericarditis was diagnosed as myocardial infarction. There are two other possibilities in our case: the patient was having both pericarditis and myocardial infarction, so stenting was not wrong option. Against this is the finding of no hypokinesia by echo and negative troponin test. The second possibility is that the infarction caused pericardial effusion that became accentuated by dual antiplatelet therapy ${ }^{(6,7)}$ Even if this is the situation the case points to the danger of DAP therapy. A third point for discussion is that the patient had autoimmune disease or systemic lupus erythematosus that was the cause of both kidney deterioration and the constrictive effusive gastritis. Laboratory results ESR $150, \mathrm{CRP}=152 \mathrm{mg} / \mathrm{l}$, but LE cell test was not done. Corticosteroids were not given to the patient.

What could have been done better? ECG should have been analyzed better; coronary angio could have been postponed. Corticosteroids may have been added but there were no other evidences of immune disease. Pericardiocentesis was needed in earlier stage but the case was constrictive pericarditis more than tamponade.

\section{Conclusions:-}

Acute pericarditis if subjected to dual antiplatelet therapy can lead to hemorrhagic pericardial effusion, then constrictive pericarditis and congestive heart failure. The absence of hypokinesia by echo and negative troponin should alert the cardiologist beside the typical ECG pattern of pericarditis.

To our knowledge this is the first report of the danger of dual antiplatelet therapy in pericarditis.

\section{Reference:-}

1. Borja Ibanez, Stefan James, Stefan Agewall, Manuel J Antunes, Chiara Bucciarelli-Ducci, Héctor Bueno, Alida L P Caforio Filippo Crea John A Goudevenos, Sigrun Halvorsen, Gerhard Hindricks, Adnan Kastrati, Mattie J Lenzen, Eva Prescott, Marco Roffi, Marco Valgimigli, Christoph Varenhorst, Pascal Vranckx, Petr Widimský, ESC Scientific Document Group. 2017 ESC Guidelines for the management of acute myocardial infarction in patients presenting with ST-segment elevation: The Task Force for the management of acute myocardial infarction in patients presenting with ST-segment elevation of the European Society of Cardiology (ESC). European Heart Journal (2017) 00, 1-66

2. A Angelinia, V Calzolarib, F Calabresea, G M Boffab, F Maddalenab, R Chioinb, G Thienea. Myocarditis mimicking acute myocardial infarction: Role of endomyocardial biopsy in the differential diagnosis. Heart $2000 ; 84: 245-250$

3. Katharina Sonderegger-lseli' Stefanie Burger, Jörg Muntwyler, Franco Salomon. Diagnostic errors in three medical eras: a necropsy study. Lancet Volume 355, Issue 9220, 10 June 2000, Pages 2027-2031

4. Wallentin L, Becker RC, Budaj A, Cannon CP, Emanuelsson H, Held C, et al. Ticagrelor versus clopidogrel in patients with acute coronary syndromes. N Engl J Med. 2009;361(11):1045-57

5. Widimský P, Gregor P. Pericardial involvement during the course of myocardial infarction. A long-term clinical and echocardiographic study. Chest. 1995;108(1):89-93.

6. Fathima Aaysha Cader, M. Maksumul Haq, Sahela Nasrin, and Md. Rezaul Karim. Pericardial tamponade due to haemorrhagic pericardial effusion as a complication of prasugrel: a case report. BMC Cardiovasc Disord. 2016; 16(1): 162.

7. Masud H. Khandaker, Raul E. Espinosa, Rick A. Nishimura, Lawrence J. Sinak, Sharonne N. Hayes, Rowlens M. Melduni, and Jae K. Oh. Pericardial Disease: Diagnosis and Management. Mayo Clin Proc. 2010 Jun; 85(6): 572-593. 